\title{
FUNCTIONAL MODEL OF COST AND TIME FOR HIGHWAY CONSTRUCTION PROJECTS
}

\author{
Jin-Fang Shr \\ Associate Professor, Department of Construction Engineering, Chung Hua University, 707, Sec 2, Wufu Rd., Hsin Chu, \\ Taiwan 300, R.O.C. \\ Wei-Tong Chen \\ Associate Professor, Department of Construction Engineering, National Yunlin University of Science and Technology, \\ 123, Section 3, University Road, Touliu, Taiwan 640, R.O.C., chenwt@ce.yuntech.edu.tw
}

Follow this and additional works at: https://jmstt.ntou.edu.tw/journal

Part of the Civil and Environmental Engineering Commons

\section{Recommended Citation}

Shr, Jin-Fang and Chen, Wei-Tong (2006) "FUNCTIONAL MODEL OF COST AND TIME FOR HIGHWAY CONSTRUCTION PROJECTS," Journal of Marine Science and Technology. Vol. 14: Iss. 3, Article 1.

DOI: $10.51400 / 2709-6998.2066$

Available at: https://jmstt.ntou.edu.tw/journal/vol14/iss3/1

This Research Article is brought to you for free and open access by Journal of Marine Science and Technology. It has been accepted for inclusion in Journal of Marine Science and Technology by an authorized editor of Journal of Marine Science and Technology. 


\section{FUNCTIONAL MODEL OF COST AND TIME FOR HIGHWAY CONSTRUCTION}

PROJECTS

\section{Acknowledgements}

The authors would like to thank Professor Jeffrey S. Russell and Professor Bin Ran for their invaluable supporting and comments. Sincerely thanks are extended to Ben Thompson, Li-Fei Huang, and Janice Bordelon for their continuous suggestion and assistance throughout the research. 


\title{
FUNCTIONAL MODEL OF COST AND TIME FOR HIGHWAY CONSTRUCTION PROJECTS
}

\author{
Jin-Fang Shr* and Wei-Tong Chen**
}

Key words: contracting, highway construction, planning and scheduling.

\begin{abstract}
It is commonly accepted that construction cost, time and quality performance has been regarded as the major success factors for a construction project. With the increasing use of innovative contracts in highway construction, the relationship between construction cost and time has become more crucial than ever. Improved control of time value has become necessary, for quantifying the functional relationship between construction cost and time. This study explores the functional relationship between highway construction cost and time. Data from projects of the Florida Department of Transportation (FDOT) in the US is utilized to develop and illustrate the quantifying model. The proposed model provides State Highway Agencies (SHAs) and contractors with increased control and understanding regarding the time value of highway construction projects.
\end{abstract}

\section{INTRODUCTION}

\section{Construction cost and time}

A project may be regarded as "successful" if it is completed within budget, on time, without any accidents, to the specified quality standards and overall client satisfaction. Construction cost-time now are increasingly important since they serve as a critical benchmark for evaluating the performance of a construction project $[3,11,17]$. Attempts to predict highway construction costs and durations represent a problem of continual concern and interest to both SHAs and contractors [2].

A relationship exists between the duration of a construction activity and its cost [8]. Similarly, construction cost and time for undertaking a construction project are interrelated. Generally, the total project cost includes both the direct and indirect costs of performing construction work. The higher curve in Figure 1 illus-

Paper Submitted 06/29/05, Accepted 12/07/05. Author for Correspondence: Wei-Tong Chen.E-mail: chenwt@ce.yuntech.edu.tw.

*Associate Professor, Department of Construction Engineering, Chung Hua University, 707, Sec 2, Wufu Rd., Hsin Chu, Taiwan 300, R.O.C.

**Associate Professor, Department of Construction Engineering, National Yunlin University of Science and Technology, 123, Section 3, University Road, Touliu, Taiwan 640, R.O.C. trates the relationship between cost and time for a construction project.

According to Callahan et al. [1] an optimum costtime balance point (normal point) exists for every construction project without considering incentive/disincentive (I/D). At this point, the construction costs of the contractor are minimized. Construction costs may increase if any variation in time occurs from this point. If the construction time from the point is reduced, the direct costs will increase while the indirect costs decrease (and vice versa) [12].

Contractors are interested in reducing project costs because such cost reductions can increase the profits and probabilities of contract awards. SHAs would have more control and understanding of the time value of highway construction projects. The development of the functional relationship between construction cost and time helps them to achieve these objectives.

\section{Hypothesis-construction cost increases with schedule compression}

Several methods of compressing the construction schedule exist. For highway construction projects, the some common methods of compressing the schedule include overtime, shifting, increasing crews, using more productive equipment, and so on. Contractors may use one or more of those methods to achieve their objective

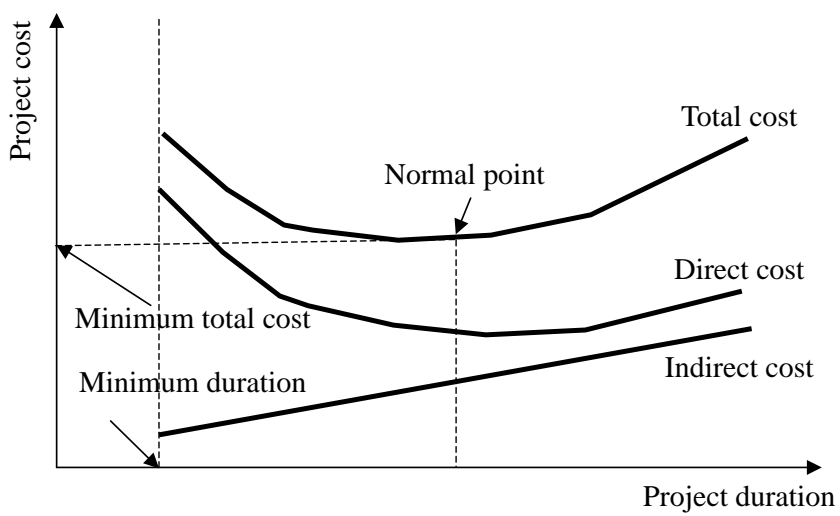

Fig. 1. Project cost and time relationship. 
of shortening the construction schedule. However, regardless of the method used, the schedule compression will cost more than a normal schedule unless taking the project I/D into account. The following are the reasons supporting this hypothesis.

\section{(1) Increasing shift length and/or workdays}

The standard workweek is 8 hours per day, 5 days per week (Monday through Friday). Longer work hours/ days introduce premium pay rates and efficiency losses. Workers tend to pace themselves for longer shifts and more days per week. An individual or crew working for 10 hours a day, 5 days a week, will not produce 25 percent more than they would working 8 hours a day, 5 days a week. While longer shifts produce some production gains, these gains have a higher unit cost than production within normal work hours. When modifications make it necessary for the contractor to resort to overtime, some of the labor costs produce no profit because of inefficiency.

Overtime work creates costs and reduces efficiency owing to the introduction of inefficient modifications. Contractors occasionally find that they need to offer overtime work as an incentive to attract sufficient manpower and skilled craftsmen to a job. When overtime is provided, the cost must be borne by the contractor; however, if overtime is necessary to accomplish modification work, the potential for introducing efficiency loses should be recognized. Figure 2 displays the result of a study designed to graphically demonstrate efficiency losses over a 4-week period for several combinations of work schedules. This data is included to provide information on trends rather than to derive rules that apply to all projects. Although the data in Figure 2 does not extend beyond the fourth week, the curves are assumed to flatten to a constant efficiency level with the continuing of each work schedule.

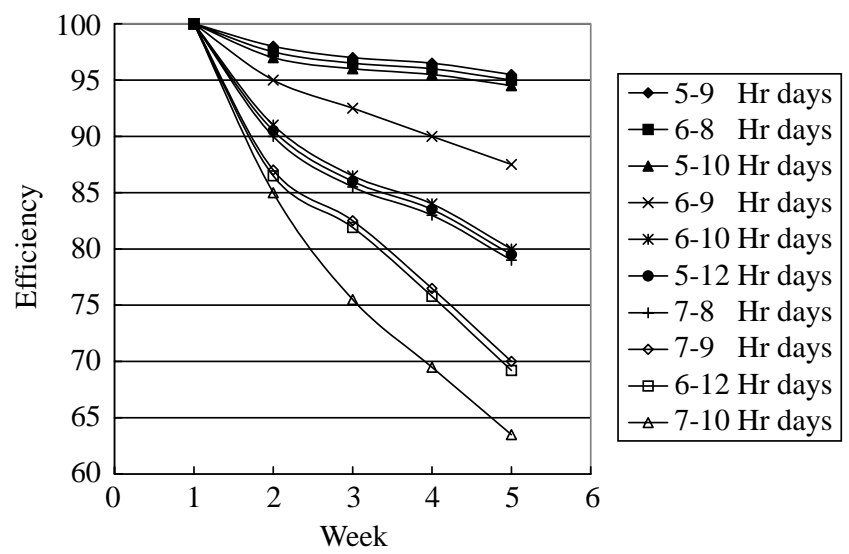

Fig. 2. Influence of work schedule on efficiency [5].

\section{(2) Multiple sifts}

The productivity inefficiencies resulting from overtime labor can be avoided by hiring additional workers and organizing two or three 8-hour shifts per day. However, additional shifts introduce other costs. These costs include additional administrative personnel, supervision, quality control, lighting, and so on. The contractor should appropriate costs due to the modification of the shift schedule used to accelerate the construction activities environmental factors such as lighting and cold weather may also influence labor efficiency.

\section{(3) Increasing crew size}

For any construction operation, the optimum crew size is the minimum number of workers required to perform the task within the allocated time period. The optimum crew size for a project or activity represents a balance between an acceptable rate of progress and the maximum production from the labor cost invested. Increasing the crew size above the minimum necessary can generally achieve faster progress, but at a higher unit cost. Each additional worker added to the crew will increase total crew productivity by a diminishing sum. Taken to the extreme, adding additional workers will contribute nothing to overall crew productivity. Figure 3 illustrates the effects of crew overloading.

\section{(4) Work force morale}

It is the responsibility of the contractor to motivate the work force and provide a psychological environment that can maximize productivity. Morale exerts an

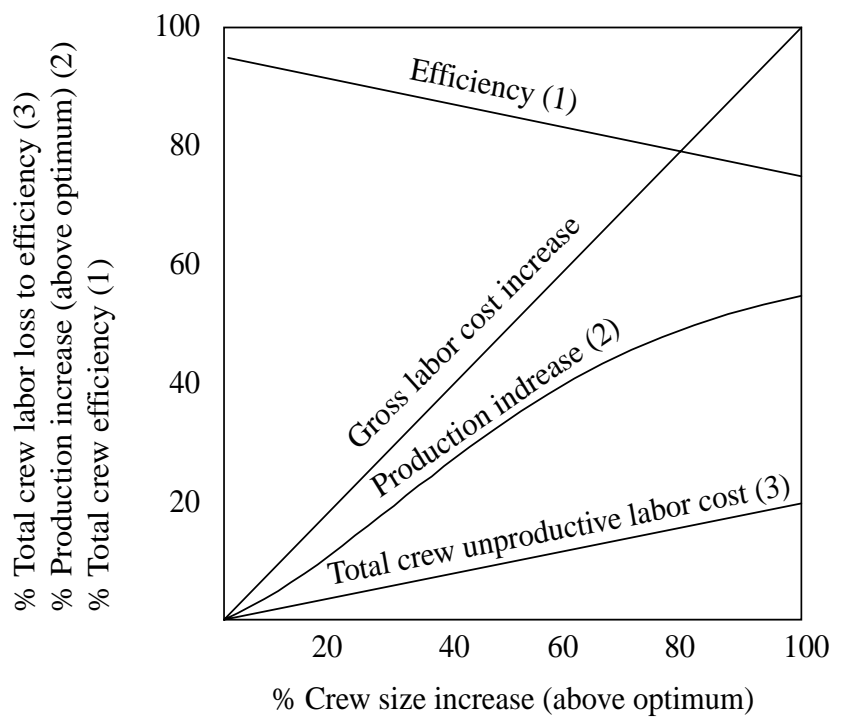

Fig. 3. Composite effects of crew overloading [5]. 
influence on productivity, but so many factors affect morale that their individual effects are not easy to quantify. The contract modifications of a project, particularly when they are numerous, adversely affect worker morale. The degree of contract modifications may influence productivity, and consequently the cost of performing the work, would normally be extremely minor compared with other causes of productivity loss. A contractor would probably find that it would cost more to maintain the records necessary to document productivity losses from reduced morale than is justified by the amount that could potentially be recovered. Modification estimates do not consider morale as a factor in productivity loss because whether morale becomes a factor is determined by how effectively the contractor fulfills his/her labor relation responsibilities [5].

\section{FUNCTIONAL RELATIONSHIP BETWEEN CONSTRUCTION COST AND TIME}

\section{Innovative contracting techniques}

In 1987, the Florida legislature in the US passed the innovative contracting statute in response to the growing demands on Florida highways owing to a rising number of road-users. The innovative contracting techniques prompted by the FDOT have recently been used in various ways, either as a single method or combined with other methods [7]. Three types of innovative contracting techniques are addressed below.

The $\mathrm{A}+\mathrm{B}$ contracting method considers both project cost and time. This method awards a project to the lowest bidder based on the cost of all of the work involved (A) and the total unit time value (B). The project time estimated by the lowest bidder thus becomes the project contract duration, and the project cost becomes the contract cost. The $\mathrm{A}+\mathrm{B}$ contracting method is used for projects with a significant level of community impact or road-user impact. This method can potentially reduce contract time. A dollar value must be calculated for each contract day before advertising the project. Ideally, a maximum number of days for which the contractor may bid should be provided.

Time cost (TC) represents the cost of delays to owner. In most cases, the TC will include the direct cost resulting from construction delays, such as temporary facilities, moving costs, and other alternate solutions. Indirect cost items encompassing both job overhead and general overhead can also be considered in the TC calculation. A variety of other general costs involving losses to the business community, reduction of potential profits and even hardship to the owner, though harder to quantify, can also be incorporated into the final calcu- lations [6].

The No Excuse Bonus concept involves providing the contractor with a significant bonus for completing a phase or a project within a specified time frame regardless of any problems or unforeseen circumstances. The bonus is tied to a drop-dead date (or an incentive date), and the contractor receives a bonus if the work is completed before that date. However, no excuse is acceptable should the contractor fail to meet the incentive date, not even bad weather or other uncontrollable events. The conditions of the standard contract are applied if the contractor selects not to pursue or fails to meet the "no excuses" deadline.

I/D contracts not only provide an incentive to the contractor for early completion, but also provide a disincentive for late completion. I/D contracts are designed to reduce total contract time by giving the contractor a time indexed incentive for early completion. The I/D amount set for each project should be supported via an estimated cost of the damage that is expected to be mitigated by early completion of the total project or critical phase of work. This determination is made during the development of the daily I/D payment. The daily I/D is calculated on a per project basis.

\section{Strategic planning for innovative contracting tech- niques}

The innovating contracting methods share the basic concept of applying a cost to the value of time. What the methods have done is to place a heavy premium on time value, thus requiring the general contractor to be much more aware of construction time. The innovative contracting methods do provide greater profits and a higher degree of risk both to owners and contractors. Currently some strategies should be retained for project owners and contractors when using the innovative contracting methods in Taiwan.

Project owners should always pose a CAP for contractor's duration and cost to allow them to reject an unreasonable bid cost and time. They should also adjust the weight of cost to time based on the emergence of the project. Most importantly, a penalty of late finish should pose and the rate of penalty should higher than that of time cost to prevent contractors under estimate the bid time to win the bids.

The general contractor should balance the amount of company resources required for bid preparation, against their chance of winning the contract, ever mindful of not only who the competition is, but the number of competitors involved. The quality and quantity of competitors should be more carefully evaluated. The chance of success bid for the contractor depends heavily on both reliable cost and time estimates. Therefore, 
contractors must strategically plan out all aspects of the project before submission of the bid to maximize profits and minimize risks.

The innovative contracting methods have been proved to be valuable technique of decreasing overall project duration and seem to be extremely cost affective $[4,6,10,14]$. Time reductions of $20-50 \%$ and cost increase of $5 \%$ were achieved in comparison to similar projects using conventional contracting methods $[6,9$, $13,15,16]$. The financial impact on final project costs associated with the reduction in construction times was very minimal, since time reduction is achieved through competition rather than actual monetary payments to the contractors. The application of these innovative contracting methods is obviously a worthy topic to be investigated in-depth in Taiwan.

\section{Research data collection}

In this research, projects used to develop the functional relationship between construction cost and time were rewarded by the FDOT using innovative contracting. These projects were all related to highway construction, and included resurfacing, replacement, lane addition, bridge repair, and miscellaneous construction. The data was obtained from 07/01/1996 to $04 / 16 / 1999$. It is essential to derive the actual project construction costs and durations because they are required as the inputs of the models developed in this study, and directly influence the results. This study only considers projects that were completed before 04/ 16/1999.

The data from the FDOT do not include additional costs such as changed orders and additional construction works following the contractor wins the bid. From the FDOT reports [7], the increase from the Award bid to the Present contract cost results from contingency supplement agreements and supplement agreements that are based on factors such as modifications of plans and changes in conditions. The increase is $1 \%$ to $5 \%$ of the Present construction cost. Additionally, all the bids are based on unit price. The quantity of each item differs between the Award bid and Present construction cost. Thus, the actual construction cost and quantity are unknowable before project completion.

This study gathered 21 projects that were completed before 04/16/1999. These 21 projects included seven A + B projects (Table 1), seven I/D projects (Table 2), and seven No excuse bonus projects (Table 3 ). Fifteen of the 21 projects are subjected to regression analysis.

From Tables 1-3, the six unused projects include one $\mathrm{A}+\mathrm{B}$ project (\#238320), three I/D projects (\#194507, \#231437 and \#195578) and two No excuse bonus projects (\#213076 and \#257024). Projects \#194507, \#231437, \#213076, and \#257024 are all finished in time - the Days used equals the Present contract time. The increases from Award bid to present construction cost exceed $7.7 \%$ for all four projects. Since these increases exceed the maximum range $(5 \%$ of the Present construction cost) permitted by the FDOT, these projects were discarded owing to possible plan modifications and/or changes of conditions. Despite project \#195578 experiencing a 68-day delay, no disincentive was charged and the Present construction cost was below the Award bid. It is not a normal condition. There might have been some change of conditions. Since no information is available in the report, this project was discarded. Additionally, the increase from Award bid to Present construction cost for project \#238320 is $9.5 \%$ which exceeds the maximum range permitted by the FDOT. The project is also being discarded.

Table 1. Results of A + B projects awarded by FDOT

\begin{tabular}{|c|c|c|c|c|c|c|c|c|c|c|}
\hline $\begin{array}{l}\text { Project } \\
\text { no. } \\
(1)\end{array}$ & $\begin{array}{c}\text { Work } \\
\text { description } \\
(2)\end{array}$ & $\begin{array}{c}\text { FDOT } \\
\text { contract est. } \\
(\$ 1,000) \\
(3)\end{array}$ & $\begin{array}{c}\text { Bid days } \\
\text { (d) } \\
\text { (4) }\end{array}$ & $\begin{array}{c}\text { Award bid } \\
(\$ 1,000) \\
(5)\end{array}$ & $\begin{array}{c}\text { Present } \\
\text { construction } \\
\text { cost }(\$ 1,000) \\
(6)\end{array}$ & $\begin{array}{l}\text { Days } \\
\text { used } \\
\text { (d) } \\
(7)\end{array}$ & $\begin{array}{c}\text { Present } \\
\text { contract time }^{b} \\
\text { (d) } \\
\text { (8) }\end{array}$ & $\begin{array}{l}\text { FDOT max. } \\
\text { allowable } \\
\text { days (d) } \\
(9)\end{array}$ & $\begin{array}{c}\mathrm{I} / \mathrm{D} \\
(\$ / \mathrm{d}) \\
(10)\end{array}$ & $\begin{array}{c}\text { I/D paid } \\
(\$ 1,000) \\
(11)\end{array}$ \\
\hline $238320^{a}$ & Add lanes & 7,354 & 385 & 6,900 & 7,557 & 372 & 437 & 485 & 3,500 & 227.5 \\
\hline 210623 & Replace & 9,213 & 300 & 9,424 & 9,718 & 311 & 381 & 650 & 6,000 & 234.9 \\
\hline 210897 & Widen & 3,359 & 101 & 3,101 & 3,151 & 145 & 162 & N/A & 2,694 & 43.1 \\
\hline 217902 & Replace & 15,378 & 429 & 14,325 & 14,612 & 460 & 468 & 739 & 2,200 & 30.8 \\
\hline 250164 & Resurface & 1,775 & 199 & 1,551 & 1,601 & 142 & 199 & N/A & 2,000 & 100 \\
\hline 257017 & Resurface & 3,119 & 120 & 2,945 & 2,991 & 135 & 142 & 135 & 5,000 & 0 \\
\hline 257060 & Resurface & 1,432 & 150 & 1,700 & 1,800 & 97 & 160 & N/A & 3,000 & 0 \\
\hline
\end{tabular}

a. Wasn't used to develop the model.

b. The present contract time is the contract time at the end of the project. That is different from the initial contract time due to change orders or other factors. 
Table 2. Results of I/D projects awarded by FDOT

\begin{tabular}{|c|c|c|c|c|c|c|c|c|}
\hline $\begin{array}{c}\text { Project } \\
\text { no. } \\
(1)\end{array}$ & $\begin{array}{c}\text { Work } \\
\text { description } \\
\text { (2) }\end{array}$ & $\begin{array}{l}\text { FDOT contract } \\
\text { estimate } \\
(\$ 1,000) \\
(3)\end{array}$ & $\begin{array}{l}\text { FDOT contract } \\
\text { time estimate. } \\
\text { (d) } \\
\text { (4) }\end{array}$ & $\begin{array}{c}\text { Award bid } \\
(\$ 1,000) \\
(5)\end{array}$ & $\begin{array}{c}\text { Present } \\
\text { construction } \\
\text { cost }(\$ 1,000) \\
(6)\end{array}$ & $\begin{array}{l}\text { Days used } \\
\text { (d) } \\
\text { (7) }\end{array}$ & $\begin{array}{c}\text { Present } \\
\text { contract } \\
\text { time }^{\text {b }}(d) \\
(8)\end{array}$ & $\begin{array}{c}\text { I/D paid } \\
(\$ 1,000) \\
(9)\end{array}$ \\
\hline $194507^{a}$ & Add lane & 6,247 & 505 & 6,199 & 6,742 & 572 & 572 & 0 \\
\hline $195578^{a}$ & Resurface & 2,598 & 200 & 2,991 & 2,972 & 301 & 233 & 0 \\
\hline $231437^{a}$ & Miscellaneous & 376 & 140 & 332 & 376 & 144 & 144 & 0 \\
\hline 229622 & Resurfacing & 7,321 & 510 & 7,112 & 7,598 & 533 & 526 & 200 \\
\hline 237453 & Add lane & 3,356 & 245 & 3,437 & 3,534 & 297 & 327 & 162 \\
\hline 242633 & Resurface & 13,764 & 440 & 14,136 & 14,617 & 515 & 575 & 475 \\
\hline 258638 & Resurface & 328 & 120 & 273 & 290 & 81 & 120 & 10 \\
\hline
\end{tabular}

a. Wasn't used to develop the model.

b. The present contract time is the contract time at the end of the project. That is different from the initial contract time due to change orders or other factors.

Table 3. Results of no excuse bonus projects awarded by FDOT

\begin{tabular}{|c|c|c|c|c|c|c|c|c|}
\hline $\begin{array}{c}\text { Project } \\
\text { no. } \\
(1)\end{array}$ & $\begin{array}{c}\text { Work } \\
\text { description } \\
(2)\end{array}$ & $\begin{array}{c}\text { FDOT contract } \\
\text { estimate } \\
(\$ 1,000) \\
(3)\end{array}$ & $\begin{array}{l}\text { FDOT contract } \\
\text { time estimate. } \\
\text { (d) } \\
\text { (4) }\end{array}$ & $\begin{array}{c}\text { Award bid } \\
(\$ 1,000) \\
(5)\end{array}$ & $\begin{array}{c}\text { Present } \\
\text { construction } \\
\text { cost }(\$ 1,000) \\
(6)\end{array}$ & $\begin{array}{l}\text { Days used } \\
\text { (d) } \\
\text { (7) }\end{array}$ & $\begin{array}{c}\text { Present } \\
\text { contract } \\
\text { time }^{\mathrm{b}}(\mathrm{d}) \\
(8)\end{array}$ & $\begin{array}{c}\text { I/D paid } \\
(\$ 1,000) \\
(9)\end{array}$ \\
\hline $194507^{\mathrm{a}}$ & Add lane & 6,247 & 505 & 6,199 & 6,742 & 572 & 572 & 0 \\
\hline $213076^{\mathrm{a}}$ & Add lane & 12,473 & 295 & 10,866 & 11,817 & 373 & 373 & 375 \\
\hline $257024^{\mathrm{a}}$ & Resurface & 782 & 110 & 931 & 1,003 & 130 & 130 & 0 \\
\hline 200704 & Bridge & 1,285 & 185 & 1,172 & 1,605 & 84 & 185 & 100 \\
\hline 240843 & Add lane & 4,169 & 340 & 4,333 & 4,415 & 401 & 401 & 300 \\
\hline 251240 & Add lane & 6,676 & 400 & 4,220 & 4,300 & 397 & 400 & 300 \\
\hline 251280 & Add lane & 4,243 & 400 & 3,177 & 3,323 & 266 & 400 & 400 \\
\hline 257074 & Resurface & 1,210 & 175 & 1,280 & 1,330 & 172 & 192 & 0 \\
\hline
\end{tabular}

a. Wasn't used to create the model.

b. The present contract time is the contract time at the end of the project. That is different from the initial contract time because of change orders or other factors.

\section{STATISTICAL ANALYSIS AND MODEL DEVELOPMENT}

\section{Model development}

Based on Callahan et al. [1], this study assumes that Award bid and Present contract Time represent the best cost-time balancing point (or normal point) while avoiding the need to consider project I/D for every construction contract listed in Tables 1-3. At this point, the contractor would have the lowest construction cost, as in Figure 1. Days used is a variation in time from the normal point that yields a corresponding construction cost- the Present construction cost. The Award bid is the price bid by the contractor. Meanwhile, the final construction cost, excluding incentives and disincentives, is termed the Present construction cost. The Present contract time is the final contract time determined by FDOT, and is adjusted for the weather or additional work. The number of days actually used by the contractor is Days Used.

Four columns of data in Tables 1 to 3 are further analyzed to establish the internal relationship between cost and time: These four columns include Award bid, Present construction cost, Present contract time, and Days used. Due to the difference in the scope of each project, two formulae (Days used - Present contract time)/(Present contract time), and (Present construction cost - Award bid)/(Award bid), are used to transform the raw data to permit further analysis, as listed in Table 4. Second, analysis of variance for investigating the relationship between costs and time is performed to determine whether or not the independent variable (Days used - Present contract time)/(Present contract time) significantly influences the dependent variable (Present construction cost - Award bid)/(Award bid). Third, in 
Table 4. Data correction for regression analysis

\begin{tabular}{|c|c|c|c|}
\hline $\begin{array}{c}\text { Project } \\
\text { no. } \\
(1)\end{array}$ & $\begin{array}{c}\text { Project } \\
\text { type } \\
(2)\end{array}$ & $\begin{array}{c}\text { (Days used - present contract time) } \\
\text { /present contract time } \\
\text { (Independent variable: Day) } \\
\text { (3) }\end{array}$ & $\begin{array}{c}\text { (Present construction cost - award bid) } \\
\text { /award bid } \\
\text { (Dependent variable: Cost) } \\
\text { (4) }\end{array}$ \\
\hline 210623 & $A+B$ & -0.1837 & 0.0312 \\
\hline 210897 & & -0.1049 & 0.0161 \\
\hline 217902 & & -0.0171 & 0.0200 \\
\hline 250164 & & -0.2864 & 0.0322 \\
\hline 257017 & & -0.0493 & 0.0156 \\
\hline 257060 & & -0.3938 & 0.0588 \\
\hline 229622 & $\mathrm{I} / \mathrm{D}$ & 0.0133 & 0.0683 \\
\hline 237453 & & -0.0917 & 0.0282 \\
\hline 242633 & & -0.1043 & 0.0340 \\
\hline 258638 & & -0.3250 & 0.0623 \\
\hline 200704 & No & -0.5459 & 0.1135 \\
\hline 240843 & excuse & 0.0000 & 0.0189 \\
\hline 251240 & bonus & -0.0075 & 0.0190 \\
\hline 251280 & & -0.3350 & 0.0460 \\
\hline 257074 & & -0.1042 & 0.0391 \\
\hline
\end{tabular}

Table 5. Equation forms of regression models

\begin{tabular}{ll}
\hline Regression model & \multicolumn{1}{c}{ Regression equation } \\
\hline Linear regression (LIN) & $Y=b_{0}+b_{1} \times X$ \\
Logarithmic regression (LOG) & $Y=b_{0}+b_{1} \times \ln X$ \\
Inverse regression (INV) & $Y=b_{0}+b_{1} / X$ \\
Quadric regression (QUA) & $Y=b_{0}=b_{1} \times X+b_{2} \times X^{2}$ \\
Cubic regression (CUB) & $Y=b_{0}+b_{1} \times X+b_{2} \times X_{2}+b_{3} \times X^{3}$ \\
Composite regression (COM) & $Y=b_{0} \times b_{1}^{X}$ \\
Power regression (POWER) & $Y=b_{0} \times X^{b_{1}}$ \\
S-curve regression (S) & $Y=e^{\left(b_{0}+b_{1}(X)\right.}$ \\
Exponential regression (EXP) & $Y=b_{0} \times e^{\left(b_{1} \times X\right)}$
\end{tabular}

Note: $X$ denotes the independent variables; $Y$ denotes the dependent variable, and $b_{0}, b_{1}, b_{2}, b_{3}$ denote constants.

association with step 2 (if significant), regression analysis is performed to fit an appropriate model, which establishes the internal relationship between cost and time.

Shown in Table 5, nine regression models were investigated to identify the best format for the collected data set. Since the independent variable contains values of zero, models INV and S can not be calculated. Models LOG and POWER cannot be calculated because the independent variable contains non-positive values. The analysis of variance of the remaining five regression models was shown in Table 6 .

The $p$-value gives the appraisal of the statistical significance of the independent factor. A $p$-value is assessed as significant and mildly significant when it is below the threshold values of 0.05 and 0.20 , correspondingly. Table 6 lists that the $p$-values of the analysis of variance are all smaller than 0.003. Thus, this study concludes that the influence of the independent factor (Days used - Present contract time)/(Present contract time) on the dependent factor (Present construction cost - Award bid)/(Award bid) is highly significant, implying these two factors are very strongly linked. This indicates that a functional relationship between these two factors can be established, and consequently it is reasonable to further apply regression analysis to fit an appropriate model.

Analyzing Table 6, the QUA and CUB regression equations yield the acceptable $R^{2}$ around 0.75 among the five types of regression models examined, indicating that the QUA and CUB regression models are able to explain $75 \%$ variability in the data and are the most appropriate cost prediction models among five examined.

Tables 7 and 8 summarize the analysis of variance procedure and variables for the QUA and the CUB regression models respectively. Analyzing the regression analysis of Table 7 indicates that the corresponding $p$-values of the Intercept, Day, and Day $\times$ Day for the QUA regression models are 0.0003, 0.1681, and 0.0072 respectively. Therefore, the parameters Intercept, Day, and Day $\times$ Day are concluded to have significant, mildly significant, and significant effects on the QUA regres- 
Table 6. Summary of various regression models

\begin{tabular}{cccccccccc}
\hline Dependent & Model & Rsq. & D.F. & F & Sigf. & $b_{0}$ & $b_{1}$ & $b_{2}$ & $b_{3}$ \\
\hline Cost & LIN & .534 & 13 & 14.89 & .002 & .0209 & -.1144 & & \\
Cost & QUA & .751 & 12 & 18.07 & .000 & .0321 & .1048 & .4658 & \\
Cost & CUB & .753 & 11 & 11.17 & .001 & .0331 & .1468 & .6884 & .2828 \\
Cost & COM & .516 & 13 & 13.86 & .003 & .0222 & .0816 & & \\
Cost & EXP & .516 & 13 & 13.86 & .003 & .0222 & -2.5053 & & \\
\hline
\end{tabular}

Note: Independent- Day. Since the independent variable contains values of zero, models INV and S cannot be calculated. The independent variable contains non-positive values. Models LOG and POWER cannot be calculated.

Table 7. Analysis of variance and variables in the QUA regression model

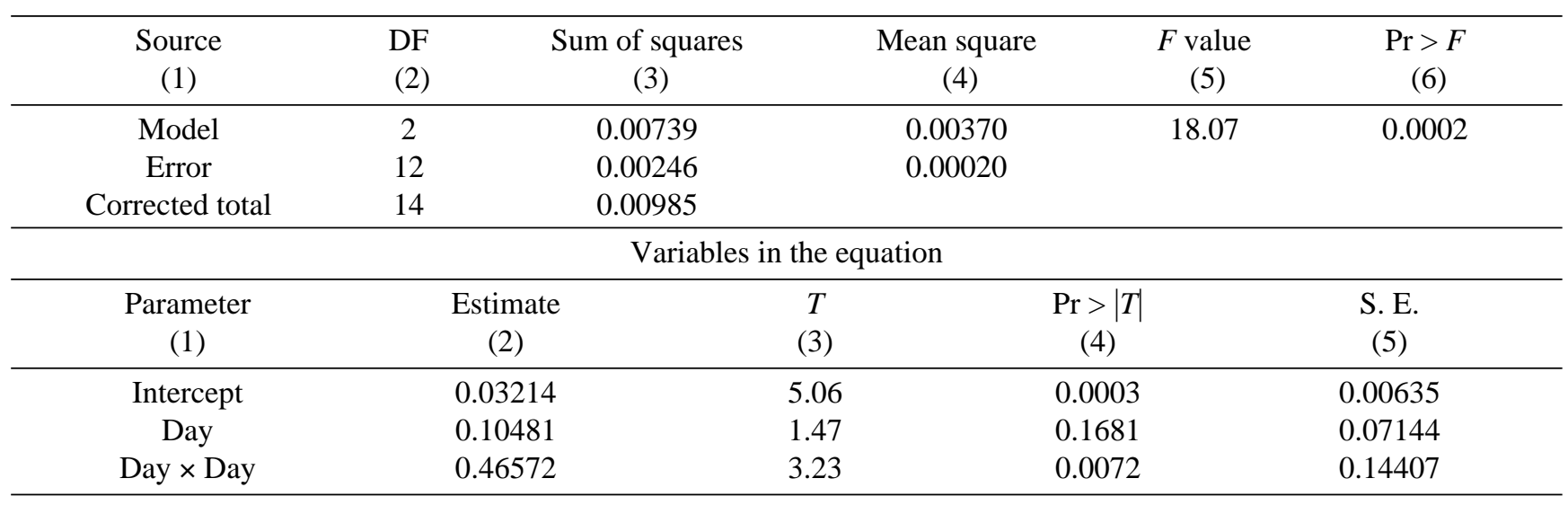

Note: Dependent variable: Cost $=($ Present construction cost - Award bid $) /$ Award bid; Independent variable: Day $=($ Days used - Present contract time)/Present contract time

Table 8. Analysis of variance and variables in the CUB regression model

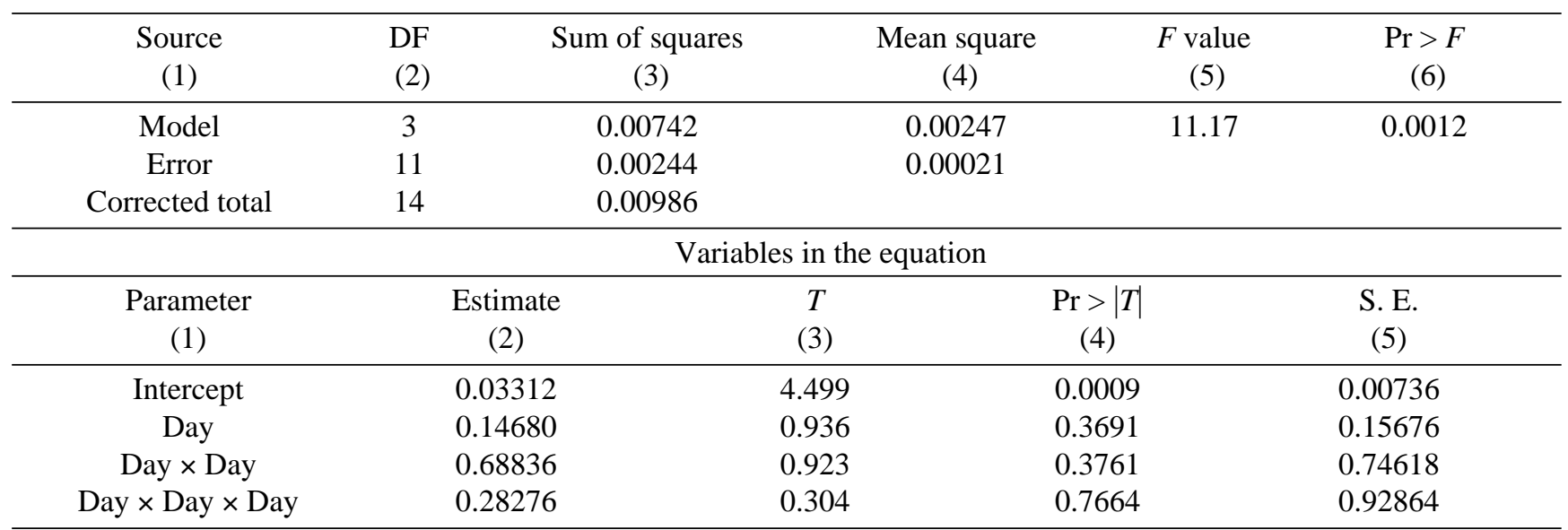

Note: Dependent variable: Cost $=($ Present construction cost - Award bid $) /$ Award bid; Independent variable: Day $=($ Days used - Present contract time)/Present contract time

sion, respectively. Analyzing the regression analysis of Table 8 shows that the corresponding $p$-values of the Intercept, Day, Day $\times$ Day, and Day $\times$ Day $\times$ Day for the
CUB regression model are $0.0009,0.3691,0.3761$, and 0.7661 respectively. Therefore, the parameters Intercept, Day, Day $\times$ Day, and Day $\times$ Day $\times$ Day are concluded to 
have significant, lowly significant, lowly significant, and no significant effects on the CUB regression, respectively. Comparing the QUA and the CUB regression models further, the former was selected mainly because the later fails to represent the variables in its model (most T-tests are not significant) although it is also equipped with a high $R^{2}$. As a result, the following fitted appropriate regression model is formulated,

$$
\begin{aligned}
& \left(\frac{C-C_{0}}{C_{0}}\right)=0.03214+0.10481\left(\frac{D-D_{0}}{D_{0}}\right) \\
& +0.46572\left(\frac{D-D_{0}}{D_{0}}\right)^{2}
\end{aligned}
$$

Where

$$
\begin{aligned}
& C \text { - Present construction cost; } \\
& D \text { - Days used; } \\
& C_{0} \text { - Award bid; and } \\
& D_{0} \text { - Present contract time }
\end{aligned}
$$

The model is extremely robust because it can be applied to all duration sizes. Most of the project costs fall in the $95 \%$ confidence interval of the predicted cost, as illustrated in Figure 4. The model was not validated due to limitations of new data resources. However, the model can be validated if more data become available in the future.

\section{Shifting the curve}

Eq. (1) displays the interrelationship between construction cost and construction time. The curve is determined following the identification of the Award Bid and Present Contract Time. Since Eq. (1) is generated from regression analysis, the Award Bid and Present Contract Time are not necessarily located at the normal

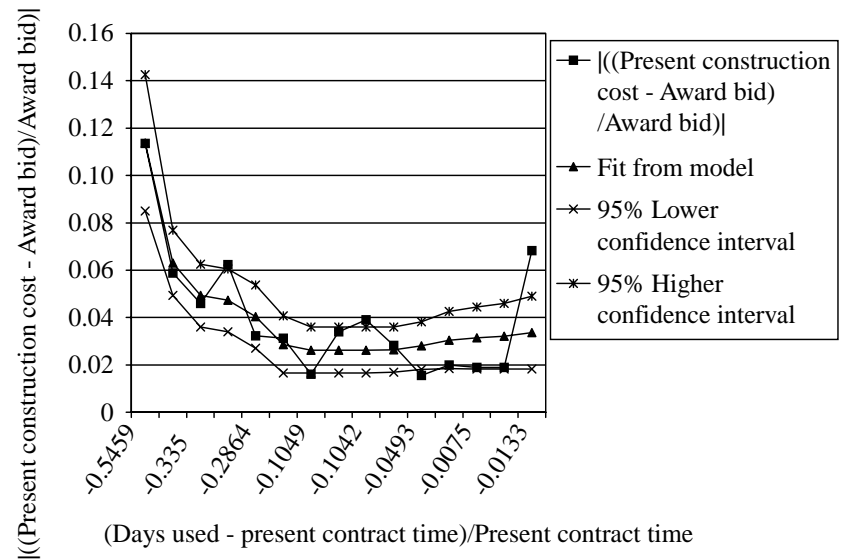

Fig. 4. Plot of the robustness data. point. That is, the "normal point" of Eq. (1) does not occur at the Award bid and Present contract time. This study assumes that the Award bid and Present contract time is a "normal point" for every construction contract. To match the research assumption, Eq. (1) must be modified to enable some shifting.

Figure 5 reveals that curve 1 is shifted so that its lowest point $\left(D_{1}, C_{1}\right)$ matches the normal point $\left(D_{0}, C_{0}\right)$ of curve 2. The normal point on curve 2 represents the construction plan in which the construction cost is the lowest associated with a specific construction time without considering project I/D. The scale of the curve does not change because of the shifting, but the lowest point of curve $1\left(D_{1}, C_{1}\right)$ approaches the normal point of curve $2\left(D_{0}, C_{0}\right)$. The shifting procedure is summarized as follows:

1. Determine $\left(D_{0}, C_{0}\right)$;

2. Use Eq. (1) and $\left(D_{0}, C_{0}\right)$ to devise the functional relationship between the construction cost and time (represented by curve 2 in Figure 5);

3. Locate the minimum point $\left(D_{1}, C_{1}\right)$ based on the functional relationship between the construction cost and time represented by curve 1 in Figure 5;

4. Calculate the distance between $\left(D_{0}, C_{0}\right)$ and $\left(D_{1}, C_{1}\right)$; and

5. Shift the functional relationship between construction cost and time using the distance from step 4 such that the minimum point occurs at $\left(D_{0}, C_{0}\right)$ in Figure 5 (shifting curve 1 to curve 2).

Following the adjustment (referring to Appendix), the equation for curve 2 in Figure 5 is as follows:

$$
\begin{aligned}
C & =1.0059 C_{0}+0.1048 C_{0}\left(\frac{D-1.1125 D_{0}}{D_{0}}\right) \\
& +0.4657 C_{0}\left(\frac{D-1.1125 D_{0}}{D_{0}}\right)^{2}
\end{aligned}
$$

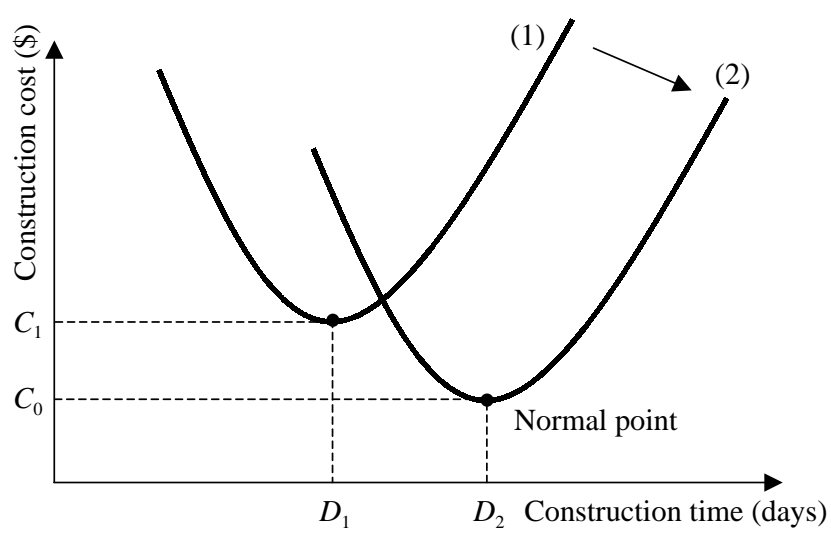

Fig. 5. Shift of the curve with the functional relationship between the construction cost and time. 
Where

$C$ - Construction cost;

$D$ - Construction time;

$C_{0}$ - Award bid; and

$D_{0}$ - Present contract time

Eq. (2) assumes every project has an internal relationship between construction cost and time. After determining the normal point (Present contract time, Award bid), the functional relationship between construction cost and time is also fixed. When using Eq. (2), $C$ and $D$ are defined as Construction cost and Construction time respectively, and both are variables. Each Construction time has a corresponding Construction cost. $C_{0}$ and $D_{0}$ may be the estimates of the engineer or contractor.

\section{Demonstrations of the proposed model}

Two example projects (\#237453 in Table 2 and \#240843 in Table 3) from the FDOT are used to explain the developed model. Project \#237453 has an Award Bid $\left(C_{0}\right)$ of $3,437 \mathrm{~K}$ and 245 Bid days $\left(D_{0}\right)$ while project \#240843 has an Award bid $\left(C_{0}\right)$ of $4,333 \mathrm{~K}$ and 340 Bid days $\left(D_{0}\right)$. This study assumes that the Bid days (FDOT Contract time estimate) and Award bid are at the normal point. Eq. (2) for project \#237453 becomes,

$$
\begin{aligned}
C & =1.0059 \times 3,437+0.1048 \times 3,437 \\
& \times((D-1.1125 \times 245) / 245)+0.4657 \times 3,437 \\
& \times((D-1.1125 \times 245) / 245)^{2} \\
& =3,457.28+360.20 \times((D-272.56) / 245) \\
& +1,600.61 \times((D-272.56) / 245)^{2} \\
& =3,457.28+1.47 \times(D-272.56)+0.0267 \\
& \times(D-272.56)^{2} \\
& =3,457+1.47 \times(D-273)+0.027 \times(D-273)^{2}
\end{aligned}
$$

From Eq. (3), if $D$ is 245 days, then

$$
\begin{aligned}
C & =3,457+1.47 \times(245-273)+0.027 \\
& \times(245-273)^{2} \\
& =3,457-41.16+21.17
\end{aligned}
$$

$$
=3,437(\mathrm{~K})
$$

Eq. (2) for project \#240843 becomes

$$
\begin{aligned}
C & =1.0059 \times 4,333+0.1048 \times 4,333 \\
& \times((D-1.1125 \times 340) / 340)+0.4657 \times 4,333 \\
& \times((D-1.1125 \times 340) / 340)^{2} \\
& =4,358.6+454.10 \times((D-378.25) / 340) \\
& +2,017.88 \times((D-378.25) / 340)^{2} \\
& =4,358.6+1.3356 \times(D-333.75)+0.017456 \\
& \times(D-333.75)^{2} 4,359+1.34 \times(D-334)+0.02 \\
& \times(D-334)^{2}
\end{aligned}
$$

From Eq. (4), if $D$ is 340 days, then

$$
\begin{aligned}
C & =4,359+1.34 \times(340-334)+0.02 \times(340-334)^{2} \\
& =4,359+8.04+0.72 \\
& =4,368(\mathrm{~K})
\end{aligned}
$$

Based on the above demonstrations, these results match the assumption that the Bid days and Award bid are on the normal point. The equations developed in this study thus can be assumed to be correct.

\section{FURTHER APPLICATIONS OF THE PROPOSED MODEL}

The model proposed in this study can provide a foundation for further development. Both owners and contractors in the highway construction industry can benefit from further developed models based on the proposed model. The proposed models could be further developed into four models that are detailed below.

\section{Model for use by contractors in determining minimum contract bids for I/D contracts}

Traditional estimates do not consider incentives to cover extra construction costs when using schedule compression. In the "I/D" contract, contractors face the problem of devising the optimum strategy for developing their bid estimate, including construction cost, construction time, and incentive/disincentive. The proposed model of the functional relationship between the construction cost and time could be further developed to 
determine the reasonable lowest bid for contractors. Figure 6 illustrates how the reasonable lowest bid for submission can be obtained for linear I/D contracts.

\section{Model for use by SHAs in determining maximum incentive for $\mathrm{I} / \mathrm{D}$ contracts}

A growing number of SHAs are using I/D contracts for highway construction. SHAs then face the problem of determining the maximum incentive awardable to contractors. The maximum incentive in an I/D contract is generally influenced by construction cost, time, and the I/D. Currently most SHAs utilize a fixed amount or fixed percentage of construction cost as a maximum incentive. Overestimation of the maximum incentive may waste public money, while underestimation reduces the effectiveness of the incentive. Neither overestimation nor underestimation of the maximum incentive is desired by the SHAs. The functional model between the construction cost and time can be further developed, as displayed in Figure 7, to derive a reasonable maximum number of days and maximum incentive for the I/D contract.

\section{Model for use by SHAs in determining minimum con- tract time for $A+B$ projects}

In the $\mathrm{A}+\mathrm{B}$ projects, SHA is forced to deal with the problem of determining a reasonable range of contract time based on the bidder submissions. Currently most SHAs do not restrict the range of B, something that potentially causes problems. First, if no low bound is set for B, a bidder can inflate the cost bid and submit an unreasonably low $\mathrm{B}$, using the excess cost bid to cover the disincentives charged for exceeding the time bid. Second, if no upper bound is set for $\mathrm{B}$, a bidder with a

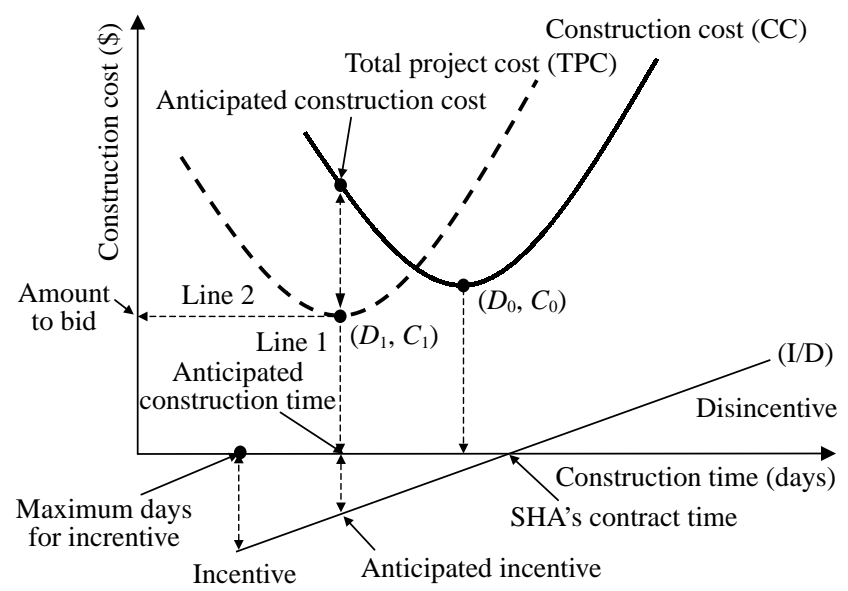

Fig. 6. Model for use by contractors in determining minimum contract bid for $\mathrm{I} / \mathrm{D}$ contracts. high $\mathrm{B}$ and a low-cost bid may be awarded the project and make unreasonable profits from incentive payments. From Figure 8, the model with the functional relationship between construction cost and time duration could be further developed to derive the minimum contract time for $\mathrm{A}+\mathrm{B}$ projects.

\section{Model for use by contractors in determining minimum contract bid for $A+B+I / D$ projects}

In the " $\mathrm{A}+\mathrm{B}+\mathrm{I} / \mathrm{D}$ " projects, contractors need to consider three parameters: construction cost (A), contract time (B), and incentive/disincentive (I/D). The motivational factors provided to the contractors under $\mathrm{A}+\mathrm{B}+\mathrm{I} / \mathrm{D}$ are twofold. Initially, competitive $\mathrm{A}+\mathrm{B}$ bidding can reduce the contractor estimates of project durations to below the time estimates of the original engineer. Furthermore, following the award of the

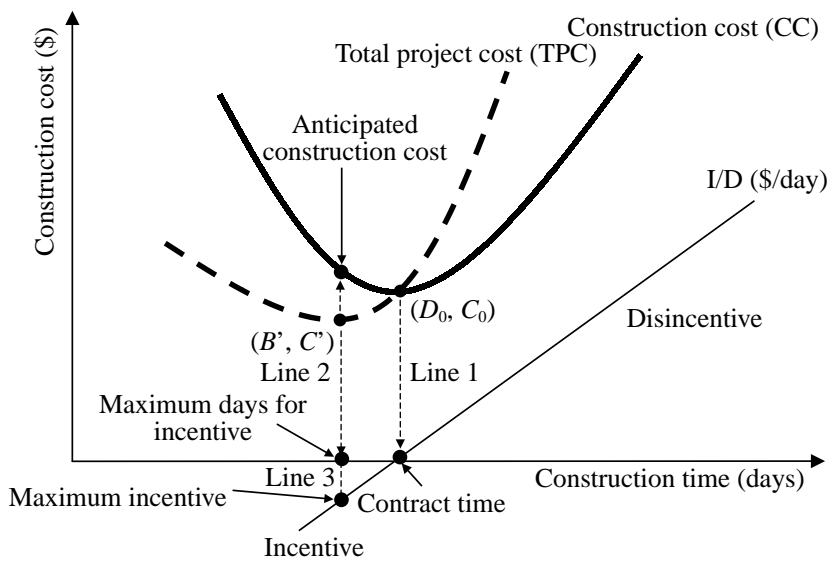

Fig. 7. Model for use by SHAs in determining maximum incentive for I/D contracts.

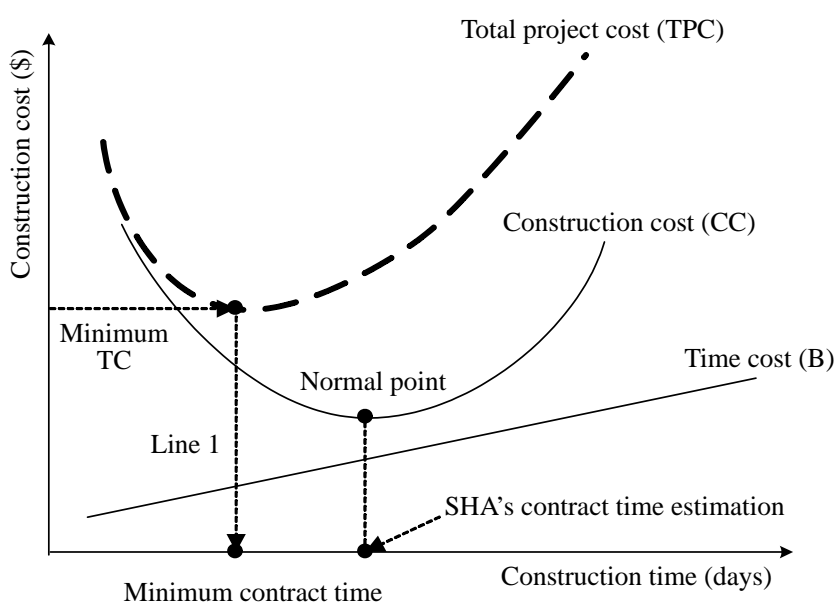

Fig. 8. Model for use by SHAs in determining minimum contract time for $A+B$ projects. 
contract, the successful contractor has additional motivation to reduce construction time further to earn additional incentive $[6,9]$. Contractors should minimize their combined estimate of $\mathrm{A}+\mathrm{B}+\mathrm{I} / \mathrm{D}$ to win the bid.

Contractors gain more interest if they can reduce $B$ while increasing $\mathrm{A}$, since $\mathrm{A}$ is the total money the contractors can gain. Furthermore, a lower B will undoubtedly create a bidding advantage. Therefore, how to use the incentive to compensate for the costs associated with shortening project duration is extremely important to the contractors of $\mathrm{A}+\mathrm{B}+\mathrm{I} / \mathrm{D}$ projects. Figure 9 reveals that the proposed model can be further extended to help contractors to derive the optimum combination of cost and time to bid and maximize the probability of wining the bid.

\section{CONCLUSIONS AND RECOMMENDATIONS}

This study compiles projects completed by the FDOT to establish a model to demonstrate the functional relationship between construction cost and time for the collected highway construction projects. This proposed model not only can give SHAs and contractors increased control and understanding of the time value of highway construction projects, but also can enable contractors to adjust construction time and cost more flexibly, making it easier for them to win a bid. The model introduced in this study can provide a foundation for:

(1) Determining the maximum days of incentive in an I/ $\mathrm{D}$ project, and a reasonable range of time duration in an A + B contract for SHAs; and

(2) Developing an improved strategy for determining the bid price for the I/D and $\mathrm{A}+\mathrm{B}+\mathrm{I} / \mathrm{D}$ projects for contractors interested in such projects.

This research demonstrates a framework of defining the functional relationship of construction cost and

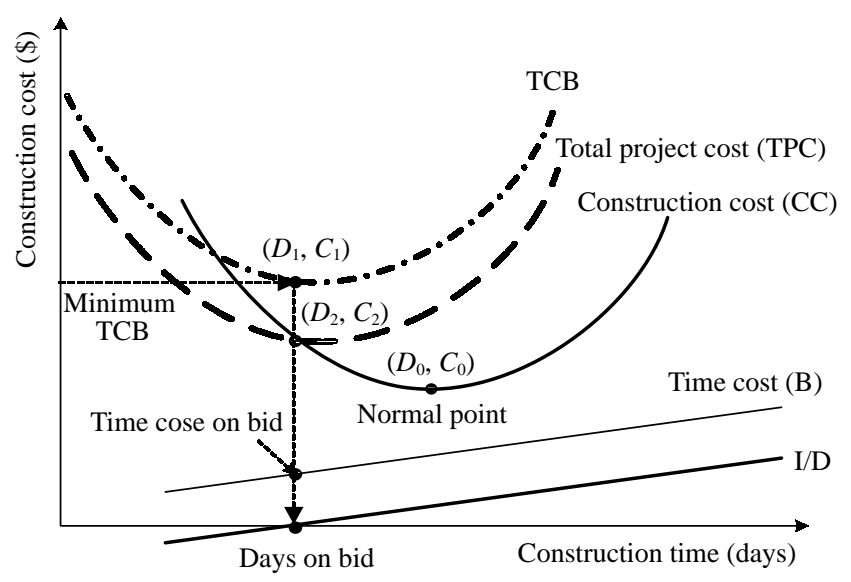

Fig. 9. Model for use by contractors in determining minimum contract bid for $A+B+I / D$ projects. time by using highway construction projects collected in the States of Florida, USA. These types of projects were selected primarily because the FDOT has inventory of detailed data, including the contract time/cost and project completion time/cost for each project. In order to perform more accurate statistical analysis of the functional relationship between the construction cost and time requires research on project selection criteria, such as project type, period, location, and amount.

The proposed framework developed in this paper also can be extended to different types of projects. However, more research on construction cost indexes, explaining the cost differences due to location, period, and economic factors, is required to enable the proposed model to be widely used. The proposed framework can be adopted by any construction client. However, the functional relationship between the construction cost and time duration needs to be created by the client in accordance with the above variables. Project information are also to be obtained properly to ensure the success of the model application.

As stated previously, the proposed framework is not suitable for projects with a great degree of change orders. Furthermore, the regression model used to represent the collected data set could be varied because the data set itself might limit the use of various regression models. For example, regression models INV and $\mathrm{S}$ can not be calculated if the independent variable contains values of zero. Therefore, additional research should be conducted with the goal of establishing acceptable general guidelines for using the proposed model in Taiwan.

\section{ACKNOWLEDGEMENTS}

The authors would like to thank Professor Jeffrey S. Russell and Professor Bin Ran for their invaluable supporting and comments. Sincerely thanks are extended to Ben Thompson, Li-Fei Huang, and Janice Bordelon for their continuous suggestion and assistance throughout the research.

\section{REFERENCES}

1. Callahan, M.T., Quackenbush, D.G., and Rowings, J.E., Construction Project Scheduling, McGraw-Hill, New York (1992).

2. Chan, A.P.C., "Time-Cost Relationship of Public Sector Projects in Malaysia," International Journal of Project Management, Vol. 19, pp. 223-229 (2001).

3. Chan, D.W.M. and Kumaraswamy, M.K., "Compressing Construction Durations: Lessons Learned from Hong Kong Building Projects," International Journal of Project 
Management, Vol. 20, pp. 23-35 (2002).

4. Chen, W.T. and Dzeng, R.-J., "Strategy Planning for Bidding on Cost/Time for Roadway Constructions in Taiwan," Proceedings of the $6^{\text {th }}$ EASEC, Taipei, Taiwan (1998).

5. Department of the Army, Modification Impact Evaluation Guide (Report No. EP 415-1-3), Department of the Army, Washington, DC (1979).

6. Ellis, R.D. and Herbsman, Z.J., Development for Improved Motorist User Cost Determination for FDOT Construction Projects, UF Engineering and Industrial Experiment Station, Gainesville, FL (1997)

7. Florida DOT, Alternative Contracting Program Preliminary Evaluation (Period Report), Tallahassee, FL (1996-1997 \& 1997-1998).

8. Harris, R.B., Precedence and Arrow Networking Techniques for Construction, John Wiley \& Sons, Inc., New York (1978).

9. Herbsman, Z., "A + B Bidding Method-Hidden Success story for Highway Construction," Journal of Construction Engineering and Management, Vol. 121, No. 4, pp. 430-437 (1995).

10. Herbsman, Z., Chen, W.T., and Epstein, W.C., "Time is Money: Innovative Contracting Methods in Highway Construction," Journal of Construction Engineering and Management, Vol. 121, No. 3, pp. 273-281 (1995).

11. Nkado, R.N., "Construction Time-Influencing Factors: the Contractor's Perspective," Construction Management and Economics, Vol. 13, pp. 81-89 (1995).

12. Shen, L., Drew, D., and Zhang, Z., "Optimal Bid Model for Price-Time Biparameter Construction Contracts," Journal of Construction Engineering and Management, Vol. 125, No. 3, pp. 204-209 (1999).

13. Shr, J.-F. and Chen, W.T., "Method to Determine Minimum Contract Bid Price for Incentive/Disincentive Highway Projects," International Journal of Project Management, Vol. 21, No. 8, pp. 601-615 (2003).

14. Shr, J.-F. and Chen, W.T., "Setting Maximum Incentive for Incentive/Disincentive Contracts for Highway Projects," Journal of Construction Engineering and Management, Vol. 130, No. 1, pp. 84-93 (2004).

15. Shr, J.-F., Ran, B., and Sung, C.W., "Method to Determine Minimum Contract Bid for A + B + I/D Projects," Journal of Construction Engineering and Management, Vol. 130, No. 4, pp. 509-516 (2004).

16. Shr, J.-F., Thompson, B.P., Russell, J.S., Ran, B., and Tserng, H.P., "Determining Minimum Contract Time for Highway Projects," Transportation Research Record, 1712, pp. 196-201 (2000).

17. Walker, D.H.T., "An Investigation Into Construction Time Performance," Construction Management and Economics, Vol. 13, No. 2, pp. 63-74 (1995).

\section{APPENDIX}

Deviation of Eq. (1)

$$
\begin{aligned}
& {\left[\frac{C-C_{0}}{C_{0}}\right]=0.03214+0.10481\left[\frac{D-D_{0}}{D_{0}}\right]} \\
& +0.46572\left[\frac{D-D_{0}}{D_{0}}\right]^{2} \\
& C=1.03214 C_{0}+0.10481 C_{0}\left(\frac{D-D_{0}}{D_{0}}\right) \\
& +0.46572 C_{0}\left(\frac{D-D_{0}}{D_{0}}\right)^{2} \\
& \frac{\partial C}{\partial D}=0.10481\left(\frac{C_{0}}{D_{0}}\right)+0.93144 C_{0}\left(\frac{D-D_{0}}{D_{0}^{2}}\right)=0 \\
& D \min =D_{1}=\left(\frac{-0.10481+0.93144}{0.93144}\right) D_{0} \\
& =0.887475 D_{0} \\
& D_{1}=0.887475 D_{0} \\
& C_{1}=1.026246 C_{0}
\end{aligned}
$$

The minimum $C$ is at $\left(0.887475 D_{0}, 1.026246 C_{0}\right)$

Distance from $\left(D_{0}, C_{0}\right)$ to $\left(0.887475 D_{0}\right.$, $\left.1.026246 C_{0}\right)=\left(-0.11252 D_{0}, 0.026246 C_{0}\right)$

Shift Eq. (1) minimum from $\left(0.887475 D_{0}\right.$, $\left.1.026246 C_{0}\right)$ to $\left(D_{0}, C_{0}\right)$ :

$$
\begin{aligned}
C+0.026246 C_{0} & =1.03214 C_{0} \\
& +0.10481 C_{0}\left(\frac{D-0.11252 D}{D_{0}}\right. \\
& +0.46572 C_{0}\left(\frac{D-0.11252 D}{D_{0}}\right. \\
C=0.10059 C_{0} & +0.1048 C_{0}\left(\frac{D-1.1125 D_{0}}{D_{0}}\right) \\
& +0.4657 C_{0}\left(\frac{D-1.1125 D_{0}}{D_{0}}\right)^{2}
\end{aligned}
$$$$
+0.10481 C_{0}\left(\frac{D-0.11252 D_{0}-D_{0}}{D_{0}}\right)
$$$$
+0.46572 C_{0}\left(\frac{D-0.11252 D_{0}-D_{0}}{D_{0}}\right)^{2}
$$ 